Journal of Engineering Sciences, Assiut University, Vol. 38, No. 2, pp. 323 -342, March, 2010.

\title{
ANALYSIS OF TRANSIENT FLOW PHENOMENON IN PRESSURIZED PIPES SYSTEM AND METHODS OF PROTECTION
}

\section{Nashaat A. Ali, Hassan I. Mohamed, Mohamed E. El-Darder and Alaa A. Mohamed}

Civil Eng. Dept, Assiut University, Assiut, Egypt

E-mail: hassanmohamed_2000@yahoo.com

(Received November 8, 2009 Accepted January 13, 2010).

Water hammer phenomenon is an important consideration in designing of many hydraulic systems due to extreme variations in pressure it causes. For example, the dramatic pressure rise can cause pipes to rupture. Accompanying the high pressure wave, there is a negative wave that can cause very low pressures leading to the possibility of contaminant intrusion or column separation. This paper investigates the effect of different parameters such as fluid density, steady flow velocity, air entrainment, pipeline material type and pipeline friction factor on transient flow in pipeline system due to pump shut down, effect of protection devices on the transient pressure head along the pipeline and effect of existence of a crack in pipeline flow. WHAMO software was used in the analysis which uses the implicit finite difference scheme for solving the momentum and continuity equations at unsteady state case. The study was applied on a pipeline composed of six segments of different diameters and elevations with a total length of $2523 \mathrm{~m}$. The flow is pumped in the pipeline by pumping station to a constant head reservoir at the end of the pipeline. The results showed that many parameters such as fluid density, steady flow velocity, air entrainment, pipeline material type and pipeline friction factor have significant effect on the water hammer phenomenon. Also, it was found that in spite of the non-return valve protects the pump from water hammer effect, increases the pressure head in the pipeline. Surge tank or air chamber fitted at the beginning of the pipeline can protect it effectively from the water hammer effect. At the end, it was found that a crack in pipeline can cause intrusion from outside the pipe to inside and inversely can cause leakage to outside or both.

KEYWORDS: water hammer, pipelines, hydraulic parameters, protection, intrusion, leakage.

\section{1- INTODUCTION}

The sudden loss of energy to a pump can be caused by an unexpected power failure, or simply because the power has been switched off. Whatever the cause, it is very important to simulate this common occurrence to determine whether dangerous pressures develop or not. The abrupt change to the flow that causes large pressure fluctuations is called water hammer. The name comes from the hammering sound that 
sometimes occurs during the phenomenon (Parmakian [9]). Many researchers studied the water hammer phenomenon along the last decades with different viewpoints, among of them Abd el-Gawad [1], Jönnsson [7], Stephenson [15], Yang [16] and many others.

Al-Khomairi [2] discussed the use of the steady-state orifice equation for the computation of unsteady leak rates from pipe through crack or rapture. It has been found that the orifice equation gives a very good estimation of the unsteady leak rate history for normal leak openings.

Mohamed [8] introduced the effect of the different parameters such as time of valve closure, pipe material rigidity and pipe roughness on the pressure damping. $\mathrm{He}$ indicated that, the pipe friction factor and the time of valve closing have a significant effect in pressure transient reduction and also, he found that the elastic pipes such as PVC are better than the rigid pipes in pressure damping. However, his study is restricted to valve closing at the end of pipeline and this case may be differ than the case of water hammer due to pump shut down.

Ramos et al. [10] carried out several simulations and experimental tests in order to analyze the dynamic response of single pipelines with different characteristics, such as pipe materials, diameters, thicknesses, lengths and transient conditions. They concluded that being the plastic pipe with a future increasing application, the viscoelastic effect must be considered, either for model calibration, leakage detection or in the prediction of operational conditions (e.g. start up or trip-off electromechanical equipment, valve closure or opening).

Samani and Khayatzadeh [12] employed the method of characteristics to analyze transient flow in pipe networks. They applied various numerical tests to examine the accuracy of these methods and found that the method in which the implicit finite difference was coupled with the method of characteristics to obtain the discretized equations which is the best compared to the others.

This study aims to investigate the effect of different parameters such as fluid density, steady flow velocity, air entrainment, pipeline material type and pipeline friction factor on transient pressure head due to pump shut down, effect of protection devices on the transient pressure head along the pipeline and effect of existence of a crack in pipeline on intrusion or leakage due to transient pressure head fluctuation.

\section{2- THEORETICAL CONSIDERATIONS}

Because of difficulty in solution of governing equations, engineers in pipelines design usually neglect this phenomenon. Recently a number of numerical methods suitable for digital computer analyses have been reported in the literature (Chaudhry and Yevjevich [4]), which may be used to solve these equations. In the following, the governing equations were solved by one of these methods.

\subsection{Governing Equations}

The governing equations for unsteady flow in pipeline are derived under the following assumptions (1) one dimensional flow i.e. velocity and pressure are assumed constant at a cross section; (2) the pipe is full and remains full during the transient; (3) no 
column separation occurs during the transient; (4) the pipe wall and fluid behave linearly elastically and (5) unsteady friction loss is approximated by steady state losses. The unsteady flow inside the pipeline is described in terms of the unsteady mass balance (continuity) equation and unsteady momentum equation, which define the state of variables of $V$ (velocity) and $\mathrm{P}$ (pressure) given as (Simpson and $\mathrm{Wu}$ [14]);

$$
\begin{aligned}
& \frac{\partial \rho}{\partial t}+V \frac{\partial \rho}{\partial x}+\rho \frac{\partial V}{\partial x}+\frac{\rho}{A} \frac{d A}{d t}=0 \\
& \frac{\partial V}{\partial t}+V \frac{\partial V}{\partial x}+\frac{1}{\rho} \frac{\partial P}{\partial x}-g \sin \alpha+\frac{f V V}{2 D}=0
\end{aligned}
$$

where $x=$ distance along the pipeline; $t=$ time, $V=$ velocity, $P=$ hydraulic pressure in the pipe, $g=$ acceleration due to gravity, $f=$ Darcy-Weisbach friction factor, $\rho=$ fluid density, $D=$ pipe diameter, $\alpha=$ pipe slope angle and $A=$ cross sectional area of the pipe.

Equation (1) is the continuity equation and takes into account the compressibility of the water and the flexibility of the material. Equation (2) is the equation of motion.

In Eq. (1), the terms $\left[\frac{\partial \rho}{\partial t}+\frac{\partial \rho}{\partial x} V\right]$ are replaced by equivalent $\frac{d P}{d t}$

where $V=\frac{d x}{d t}$ and $\frac{d \rho}{d t}=\frac{\rho}{K} \frac{d p}{d t}$

$K=$ bulk modulus of the fluid

Therefore, one can have

$$
\frac{d P}{d t}\left[\frac{1}{K}+\left(\frac{1-v^{2}}{E}\right) \frac{d}{e}\right]+\frac{\partial V}{\partial x}=0
$$

Putting $\frac{1}{\rho c^{2}}=\left[\frac{1}{K}+\left(\frac{1-v^{2}}{E}\right) \frac{d}{B}\right]=\frac{1}{K}\left[1+\frac{K c_{1} d}{E B}\right]$

Where $c=$ wave speed, $v=$ Poisson ratio, $E=$ Young's modulus of elasticity, $e=$ pipe wall thickness and $c_{1}=\left(1-v^{2}\right)$. Dividing the result by $\gamma$ yields

$$
\left[\frac{\partial H}{\partial t}+\frac{\partial H}{\partial x} V\right]+\frac{c^{2}}{g} \frac{\partial V}{\partial x}=0
$$

where $H$ is the piezometric head, pressure head plus the elevation head The term $\frac{\partial H}{\partial x}$ is small compared to $\frac{\partial H}{\partial t}$ and it is often neglected. In terms of discharge, Eq. (5) becomes

$$
\frac{\partial H}{\partial t}+\frac{\partial Q}{\partial x} \frac{c^{2}}{g A}=0
$$

\subsection{Implicit Finite Difference Method}

The continuity and momentum equations form a pair of hyperbolic, partial differential equations for which an exact solution can not be obtained analytically. However other methods have been developed to solve the water hammer equations. If the equations are hyperbolic it means the solutions follow certain characteristic pathways. For the water hammer equation, the wave speed is the characteristic. The implicit finite difference method is a numerical method used for solving the water hammer equations. 
The implicit method replaces the partial derivatives with finite differences and provides a set of equations that can then be solved simultaneously. The computer program WHAMO uses the implicit finite-difference technique but converts its equations to a linear form before it solves the set of equations (Fitzgerald and Van Blaricum [5]). The solution space is discretized into the $\mathrm{x}$-t plane so that at any point on the grid $(x, t)$ there is a certain $\mathrm{H}$ and $\mathrm{Q}$ for the that point, $H(x, t)$ and $Q(x, t)$ as shown in Fig. (1).

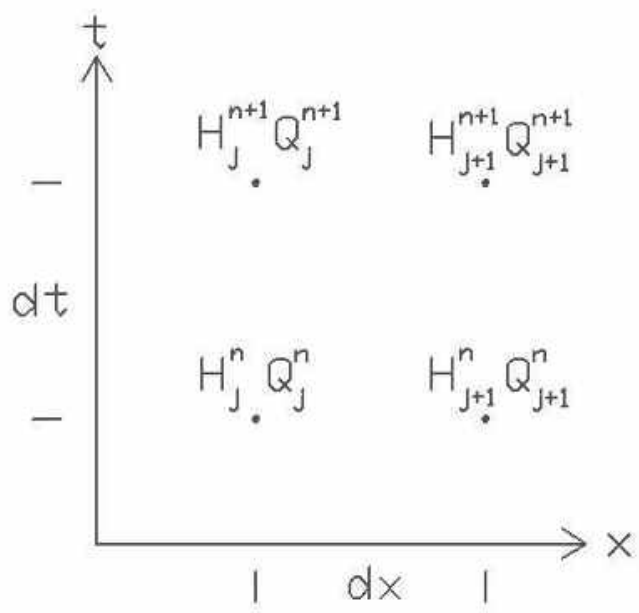

Fig. (1): Finite difference grid.

The momentum equation and the continuity equation can be represented in a short form by introducing the following coefficients for the known values in a system. Using the same notation as the WHAMO program the coefficients are as follows:

$$
\begin{aligned}
& \alpha_{\mathrm{j}}=\frac{2 \Delta t c^{2} \theta}{g A_{j} \Delta x_{j}} \\
& \beta_{j}=\left(H_{\mathrm{nj}+1}-H_{\mathrm{nj} j}\right)+\frac{(1-\theta)}{\theta} \alpha_{j}\left(Q_{\mathrm{nj}}-Q_{\mathrm{nj}+1}\right) \\
& \gamma_{\mathrm{j}}=\frac{\Delta x_{j}}{2 g \theta A_{j} \Delta t}
\end{aligned}
$$

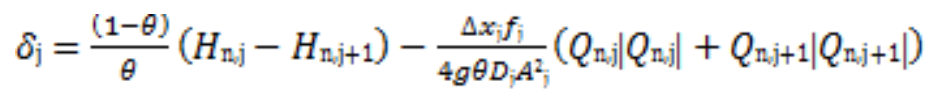

where $\theta$ is the weighting factor. All the parameters for the coefficient should be known from the properties of the pipe or the values of head and flow at the previous time step. With the known coefficients, the momentum and continuity equations of the $j^{\text {th }}$ segment of the pipe become:

Momentum: $-H_{\mathrm{nj}+1}+H_{\mathrm{n}+1, j+1}+\gamma_{\mathrm{j}}\left(Q_{\mathrm{n}+1, j}+Q_{\mathrm{n}+1 j+1}\right)=\delta_{\mathrm{j}}$

Continuity: $\quad H_{\mathrm{n} j+1}+H_{\mathrm{n}+1, j+1}+\alpha_{\mathrm{j}}\left(Q_{\mathrm{m}+1, j+1}-Q_{\mathrm{n}+1, j}\right)=\beta_{\mathrm{j}}$

Now, with equations for the all the links and nodes in the system, the initial and boundary conditions, a matrix of the linear system of equations can be set up to solve for head and flow everywhere, simultaneously, for the first time step. The 
process is repeated for the next time step, and again for the next step until the specified end of the simulation.

\section{3- CASE STUDY}

A pipeline of six parts transmits fluid from low level to high level as shown in Fig. (2) is used in this study. This pipeline profile was adopted from Burrows and Qiu [3]. The study was divided to three parts. In part one, the different parameters which affect the water hammer phenomenon were studied. In part two, effect of methods of protection were studied. In the third part, effect of leakage and intrusion from and to pipeline were studied. The length, diameters and levels of the different parts of the pipeline are shown in Fig. (2). Table (1) shows the studied variables. WHAMO software was used to calculate the change in pressure heads along the pipeline with time due to pump shut down.

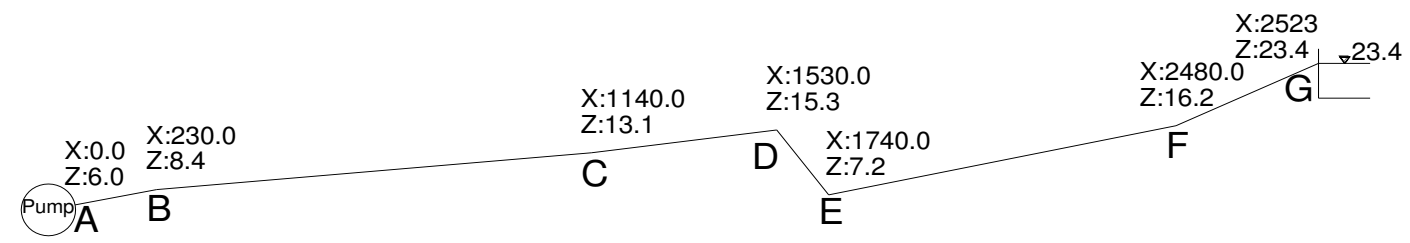

$$
D_{\mathrm{AB}}=D_{\mathrm{BC}}=0.325 \mathrm{~m}, D_{\mathrm{CD}}=D_{\mathrm{DE}}=D_{\mathrm{EF}}=0.315 \mathrm{~m}, D_{\mathrm{FG}}=0.305 \mathrm{~m}
$$

Fig. (2): Pipeline profile.

Table 1: The different parameters used in this study

\begin{tabular}{|c|c|c|c|}
\hline Study case & Parameter & Value & Units \\
\hline \multirow{5}{*}{ Part 1} & fluid density $(\rho)$ & $900,1000,1100$ and 1200 & $\mathrm{~kg} / \mathrm{m}^{3}$ \\
\hline & steady flow velocity $(V)$ & $1,1.6$ and 1.8 & $\mathrm{~m} / \mathrm{sec}$. \\
\hline & air concentration & $0,0.1,0.5,1.0$ and $2.0 \%$ & - \\
\hline & pipe elasticity $(E)$ & $3.3,20,24,165$ and 210 & $\mathrm{GN} / \mathrm{m}^{2}$ \\
\hline & pipe friction factor $(f)$ & $0.0,0.005$ and 0.01 & - \\
\hline \multirow{3}{*}{ Part 2} & Non-return valve & \multirow{3}{*}{\multicolumn{2}{|c|}{$\begin{array}{c}\quad \rho=1000 \mathrm{~kg} / \mathrm{m}^{3}, V=1 \mathrm{~m} / \mathrm{sec} \text {, air } \\
\text { concentration }=0 \%, E=3.3 \mathrm{GN} / \mathrm{m}^{2}, \text { pipe } \\
\text { wall thickness }=1.69 \mathrm{~cm} \text { and } f=0.01\end{array}$}} \\
\hline & Open surge tank & & \\
\hline & Air chamber & & \\
\hline \multirow{3}{*}{ Part 3} & Intrusion & \multirow{3}{*}{\multicolumn{2}{|c|}{$\begin{array}{c}\rho=1000 \mathrm{~kg} / \mathrm{m}^{3}, V=1 \mathrm{~m} / \mathrm{sec} ., \text { air } \\
\text { concentration }=0 \%, E=3.3 \mathrm{GN} / \mathrm{m}^{2} \text {, pipe } \\
\text { wall thickness }=1.69 \mathrm{~cm} \text { and } f=0.01\end{array}$}} \\
\hline & Leakage & & \\
\hline & Intrusion and leakage & & \\
\hline
\end{tabular}

\section{4- RESULTS AND DISCUSSIONS}

\subsection{Effect of Change of Some Variables on Transient Pressure Head}

In this section, the result of the effect of some variables on transient pressure head due to pump shut down, such as fluid density, steady flow velocity, air entrainment, pipeline material type and pipeline friction factor are presented. It has to be mentioned 
that, the pipeline was not protected against water hammer phenomenon through this part of study except the case of friction factor; non-return valve is installed at the beginning of the pipeline.

\subsubsection{Effect of Change in Fluid Density $(\rho)$}

The fluid density was changed four times, $900,1000,1100$ and $1200 \mathrm{~kg} / \mathrm{m}^{3}$. The other variables were taken as constant where friction factor $=0.01$, pipe material is PVC with modules of elasticity $=3.3 \mathrm{GN} / \mathrm{m}^{2}$, pipe wall thickness $1.69 \mathrm{~cm}$ and initial flow velocity before pump shut down is $1 \mathrm{~m} / \mathrm{sec}$. Figures (3) and (4) show the variation in $P_{\max } / P_{o}$ ratio and $\mathrm{P}_{\min } / \mathrm{P}_{\mathrm{o}}$ ratio, respectively, where $\mathrm{P}_{\max }$ is the maximum transient pressure, $\mathrm{P}_{\min }$ is the minimum transient pressure along the pipeline and $P_{o}$ is the steady flow pressure at position of $\mathrm{P}_{\max }$ and $\mathrm{P}_{\min }$. As shown from Fig. (3), the maximum transient pressure to steady flow pressure ratio increases due to increase in flow density from 900 to 1000 $\mathrm{kg} / \mathrm{m}^{3}$ by nearly $1 \%$ then decreases due to the increase in flow density from 1000 to $1200 \mathrm{~kg} / \mathrm{m}^{3}$ by nearly $8 \%$. Figure (4) shows that minimum transient pressure to steady flow pressure ratio increases due to the increase in flow density from 900 to 1000 $\mathrm{kg} / \mathrm{m}^{3}$ by nearly $5 \%$ and from 1000 to $1100 \mathrm{~kg} / \mathrm{m}^{3}$ by nearly $0.3 \%$ then decreases due to the increase in flow density from 1100 to $1200 \mathrm{~kg} / \mathrm{m}^{3}$ by nearly $5 \%$.

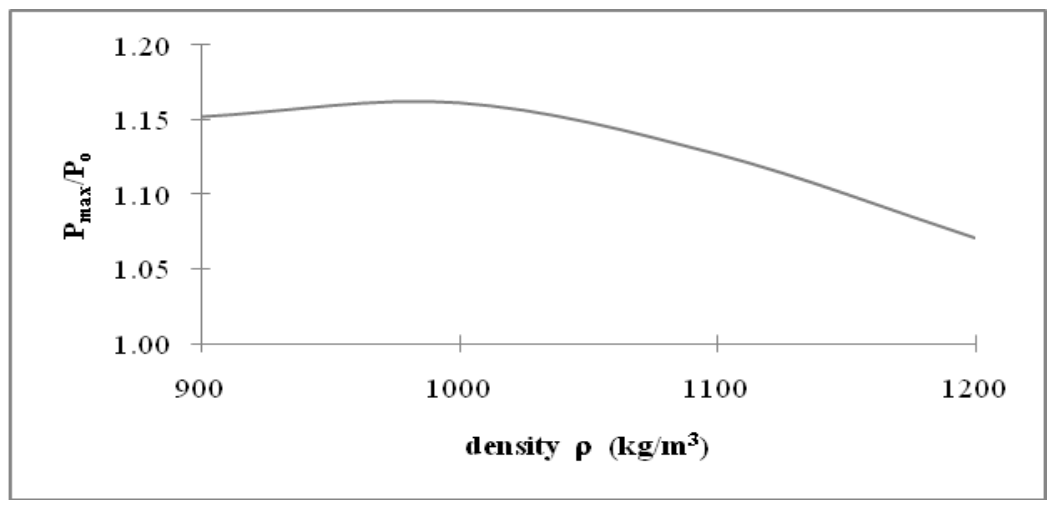

Fig. (3): Dimensionless maximum pressure in the pipe versus the fluid density.

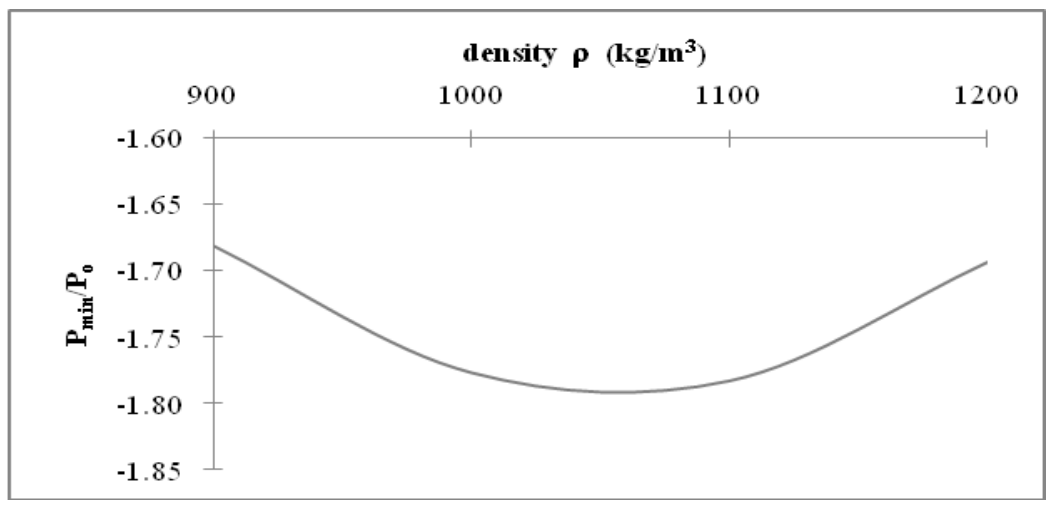

Fig. (4): Dimensionless minimum pressure in the pipe versus the fluid density. 


\subsubsection{Effect of Steady Flow Velocity (V)}

The initial velocity in the pipeline was changed three times, $1.0,1.6$ and $1.8 \mathrm{~m} / \mathrm{sec}$., by using one pump, two similar pumps and three similar pumps on parallel, respectively. The other variables were taken as constant where friction factor $(f)=0.01$, fluid density $(\rho)=1000 \mathrm{~kg} / \mathrm{m}^{3}$ (fluid is water) and pipe material is PVC with modules of elasticity $=3.3 \mathrm{GN} / \mathrm{m}^{2}$ and pipe wall thickness $1.69 \mathrm{~cm}$. Figures (5) and (6) depict the variation in $\mathrm{P}_{\max } / \mathrm{P}_{\mathrm{o}}$ ratio and $\mathrm{P}_{\min } / \mathrm{P}_{0}$ ratio, respectively. where $\mathrm{P}_{\max }$ is the maximum transient pressure, $\mathrm{P}_{\min }$ is the minimum transient pressure and $\mathrm{P}_{\mathrm{o}}$ is the steady flow pressure at position of $\mathrm{P}_{\max }$ and $\mathrm{P}_{\min }$. As shown in Fig. (5), the maximum transient pressure to steady flow pressure ratio increases due to the increase in steady flow velocity from 1 to $1.6 \mathrm{~m} / \mathrm{sec}$. by nearly $1.5 \%$ and decreases due to the increase in steady flow velocity from 1.6 to $1.8 \mathrm{~m} / \mathrm{sec}$. by nearly $0.2 \%$. Figure (6) shows that the minimum transient pressure to steady flow pressure ratio decreases due to the increase in steady flow velocity from 1 to $1.6 \mathrm{~m} / \mathrm{sec}$. by nearly $6 \%$ and from 1.6 to $1.8 \mathrm{~m} / \mathrm{sec}$. by nearly $5 \%$.

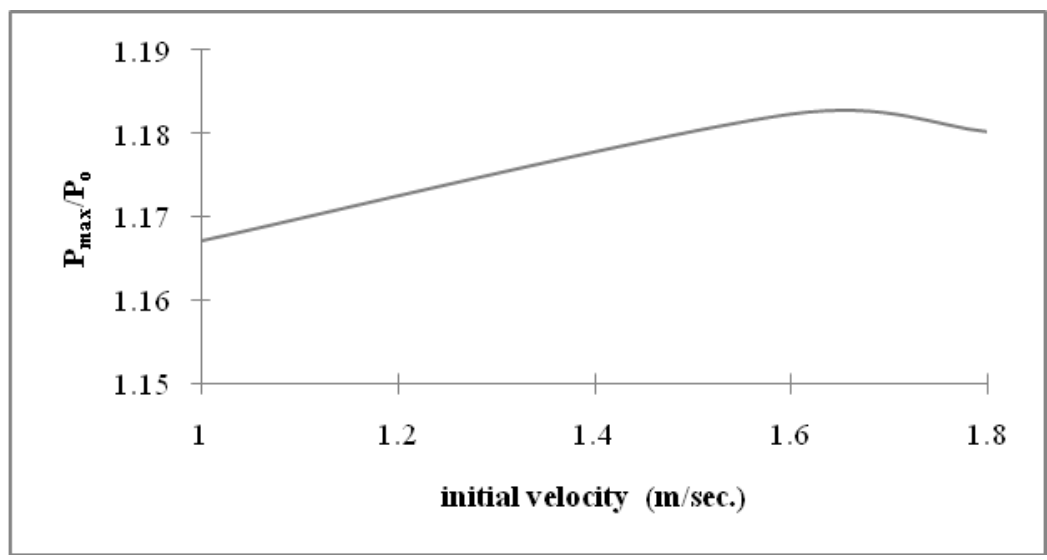

Fig. (5): Dimensionless maximum pressure in the pipe versus the fluid initial velocity.

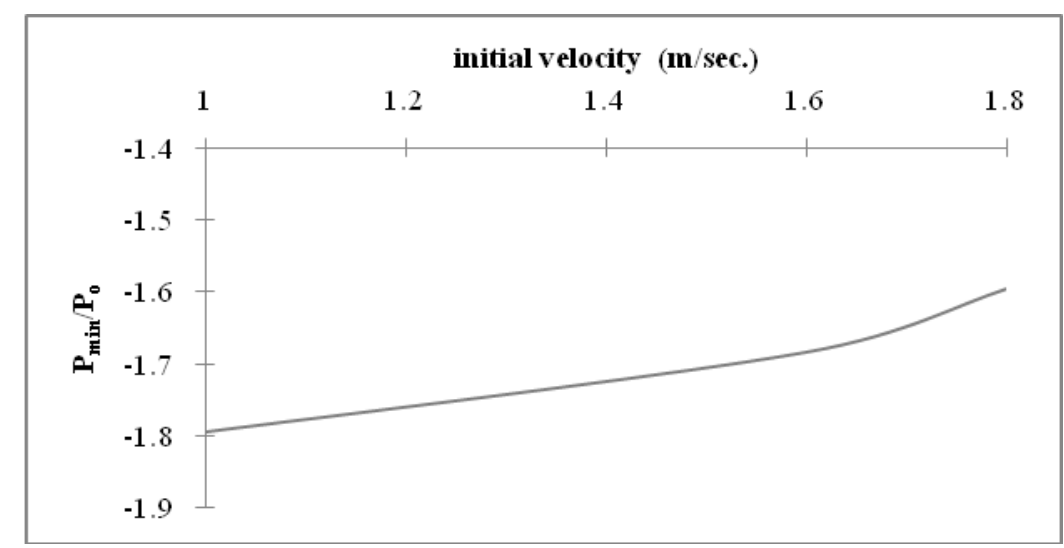

Fig. (6): Dimensionless minimum pressure in the pipe versus the fluid initial velocity. 


\subsubsection{Effect of Change in Air Concentration in the Fluid}

Air concentration was changed five times, $0,0.1,0.5,1.0$ and $2.0 \%$. The other variables were taken as constant where friction factor $(f)=0.01$, pipe material is PVC with modules of elasticity $=3.3 \mathrm{GN} / \mathrm{m}^{2}$, pipe wall thickness $1.69 \mathrm{~cm}$, initial flow velocity before pump shut down is $1 \mathrm{~m} / \mathrm{sec}$, fluid density $\left(\rho_{\text {liq }}\right)=1000 \mathrm{~kg} / \mathrm{m}^{3}$ (fluid is water). Figures (7) and (8) present the variation in $\mathrm{P}_{\max } / \mathrm{P}_{\mathrm{o}}$ ratio and $\mathrm{P}_{\min } / \mathrm{P}_{\mathrm{o}}$ ratio, respectively, where $P_{\max }$ is the maximum transient pressure, $P_{\min }$ is the minimum transient pressure and $\mathrm{P}_{\mathrm{o}}$ is the steady flow pressure at position of $\mathrm{P}_{\max }$ and $\mathrm{P}_{\min }$. As shown in Fig. (7) the maximum transient pressure to steady flow pressure ratio decreases due to the increase in air concentration from 0 to $0.1 \%$ by nearly $12 \%$ then increases due to the increase in air concentration from 0.1 to $0.5 \%$ by nearly $20 \%$ then decreases due to the increase in air concentration from 0.5 to $1.0 \%$ by nearly $0.5 \%$ and finally increases due to the increase in air concentration from 1.0 to $2.0 \%$ by nearly $7 \%$. Figure (8) shows that the minimum transient pressure to steady flow pressure ratio increases due to the increase in air concentration from 0 to $0.1 \%$ by nearly $2 \%$ and decreases due to the increase in air concentration from 0.1 to $2.0 \%$ by nearly $17 \%$.

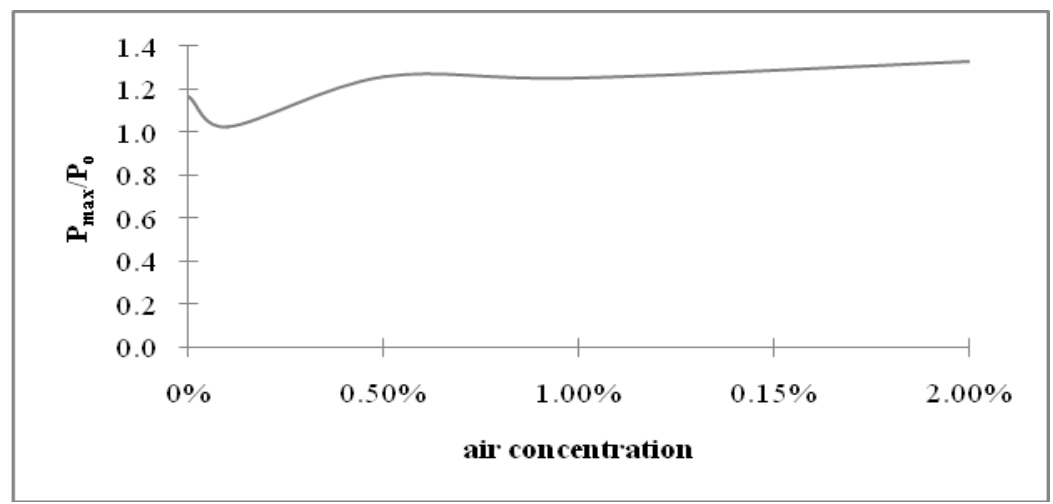

Fig. (7): Dimensionless maximum pressure in the pipe versus air concentration in the fluid.

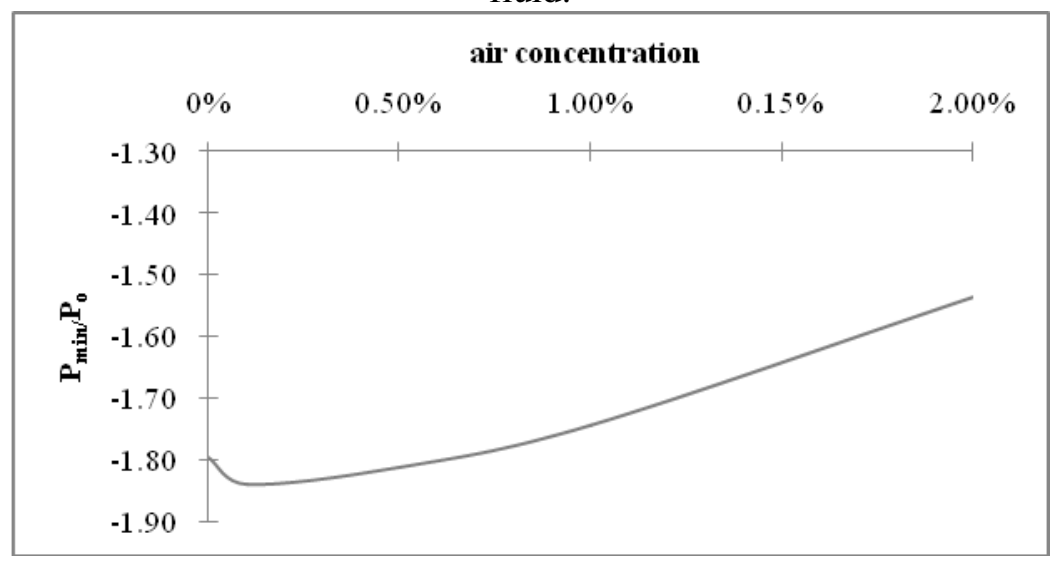

Fig. (8): Dimensionless minimum pressure in the pipe versus air concentration in the fluid. 


\subsubsection{Effect of Change in Pipe Elasticity (E)}

Five materials were studied PVC, concrete, asbestos cement (AC), ductile iron and steel. The other variables were taken as constant where friction factor $(f)=0.01$, fluid density $(\rho)=1000 \mathrm{~kg} / \mathrm{m}^{3}$ (fluid is water), initial flow velocity before pump shut down is $1 \mathrm{~m} / \mathrm{sec}$, there is no air in the water and the pipe wall thickness for the all pipe materials were taken $1.69 \mathrm{~cm}$. The used materials data is shown in table (2) and were adopted from Jones and Bosserman [6], Richard and Svindland [11] and Sharp and Sharp [13].

Table 2: Properties of used pipe materials

\begin{tabular}{|c|c|}
\hline Pipe material & Modules of elasticity \\
\hline PVC & $3.3 \mathrm{GN} / \mathrm{m}^{2}$ \\
\hline Concrete & $20 \mathrm{GN} / \mathrm{m}^{2}$ \\
\hline AC & $24 \mathrm{GN} / \mathrm{m}^{2}$ \\
\hline Ductile iron & $165 \mathrm{GN} / \mathrm{m}^{2}$ \\
\hline Steel & $210 \mathrm{GN} / \mathrm{m}^{2}$ \\
\hline
\end{tabular}

The variation in $\mathrm{P}_{\max } / \mathrm{P}_{o}$ ratio and $\mathrm{P}_{\min } / \mathrm{P}_{\mathrm{o}}$ ratio is shown in Figs. (9) and (10), respectively, where $\mathrm{P}_{\max }$ is the maximum transient pressure, $\mathrm{P}_{\min }$ is the minimum transient pressure and $\mathrm{P}_{\mathrm{o}}$ is the steady flow pressure at position of $\mathrm{P}_{\max }$ and $\mathrm{P}_{\min }$. As the shown from Fig. (9), maximum transient pressure to steady flow pressure ratio decreases due to the increase in pipe material elasticity from 3.3 to $20 \mathrm{GN} / \mathrm{m}^{2}$ by nearly $14 \%$ and from 20 to $210 \mathrm{GN} / \mathrm{m}^{2}$ by nearly $3 \%$. Figure (10) shows that minimum transient pressure to steady flow pressure ratio decreases due to the increase in pipe material elasticity from 3.3 to $20 \mathrm{GN} / \mathrm{m}^{2}$ by nearly $10 \%$, from 20 to $24 \mathrm{GN} / \mathrm{m}^{2}$ by nearly $14 \%$ and from 24 to $165 \mathrm{GN} / \mathrm{m}^{2}$ by nearly $23 \%$ then increases due to the increase in pipe material elasticity from 165 to $210 \mathrm{GN} / \mathrm{m}^{2}$ by nearly $2 \%$.

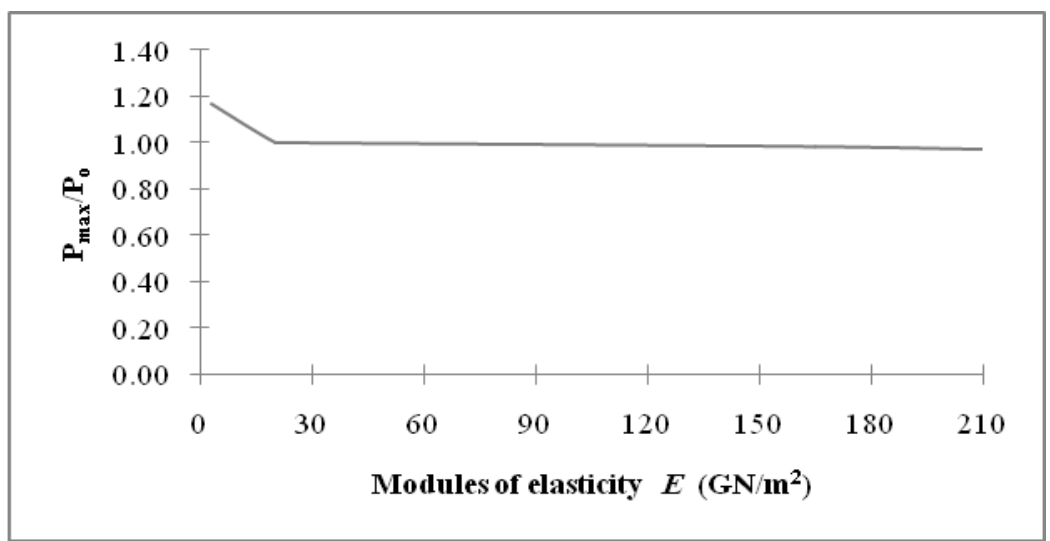

Fig. (9): Dimensionless maximum pressure in the pipe versus the pipe modules of elasticity. 


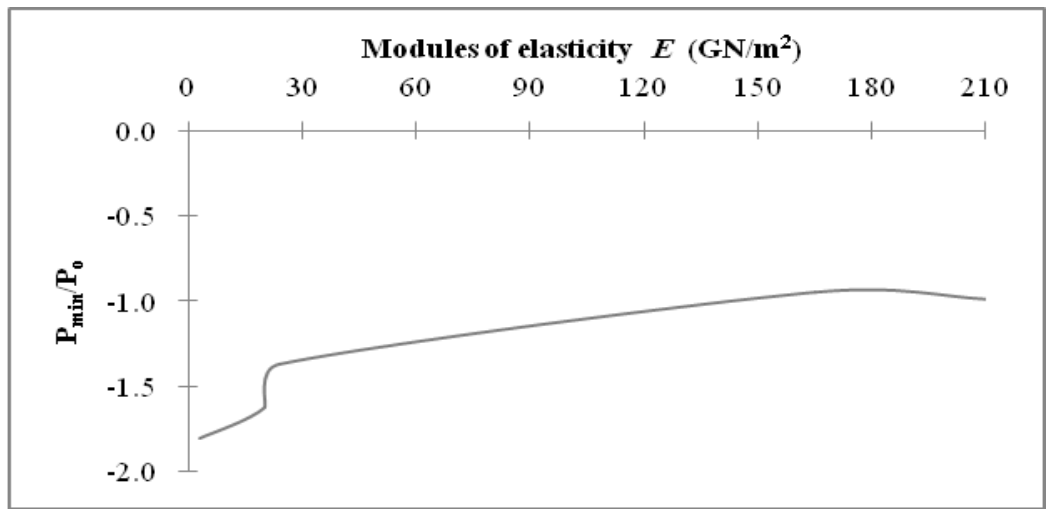

Fig. (10): Dimensionless minimum pressure in the pipe versus the pipe modules of elasticity.

\subsubsection{Effect of Change in Pipe Friction Factor ( $f$ )}

To investigate the effect of change in friction factor on transient pressure head, three cases were studied and the friction factor values in those cases were 0.0, 0.005 and 0.01 . The other variables were taken as constant where pipe material is PVC with modules of elasticity $=3.3 \mathrm{GN} / \mathrm{m}^{2}$, pipe wall thickness $1.69 \mathrm{~cm}$, fluid density $(\rho)=1000$ $\mathrm{kg} / \mathrm{m}^{3}$ (fluid is water), initial flow velocity before pump shut down is $1 \mathrm{~m} / \mathrm{sec}$. and there is no air in the water. A non-return valve was used at beginning of the pipeline to illustrate the effect of change in pipe friction on transient pressure head. Figures (11) and (12) show the variation in $\mathrm{P}_{\max } / \mathrm{P}_{\mathrm{o}}$ ratio and $\mathrm{P}_{\min } / \mathrm{P}_{\mathrm{o}}$ ratio, respectively, where $\mathrm{P}_{\max }$ is the maximum transient pressure, $P_{\min }$ is the minimum transient pressure and $P_{o}$ is the steady flow pressure at position of $\mathrm{P}_{\max }$ and $\mathrm{P}_{\min }$. Figure (11) shows that the maximum transient pressure to steady flow pressure ratio decreases due to the increase in friction factor from 0 to 0.01 by nearly $6 \%$. Figure (12) shows that the minimum transient pressure to steady flow pressure ratio decreases due to the increase in friction factor from 0 to 0.01 by nearly $17 \%$.

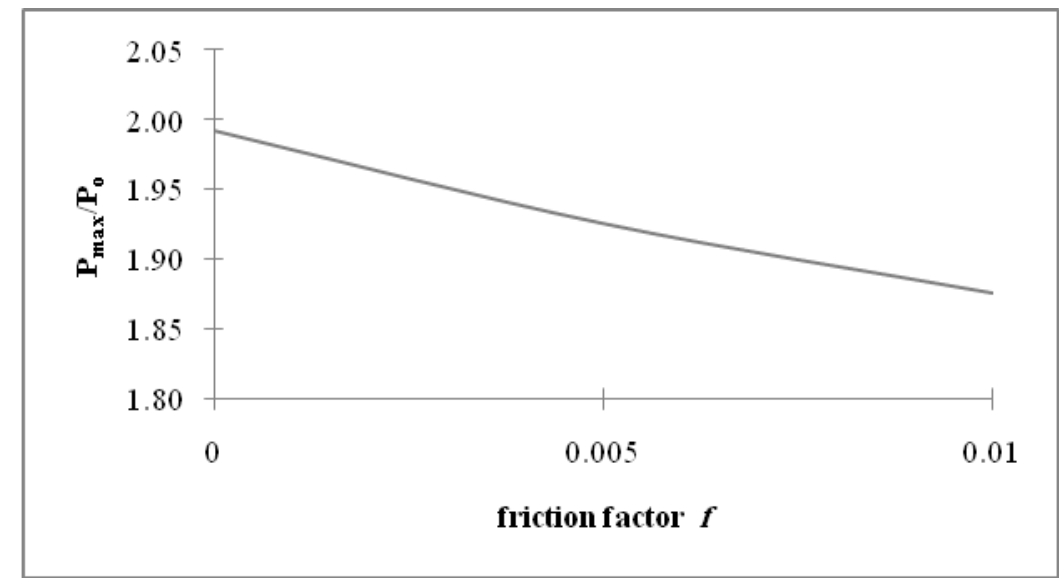

Fig. (11): Dimensionless maximum pressure in the pipe versus the pipe friction factor. 


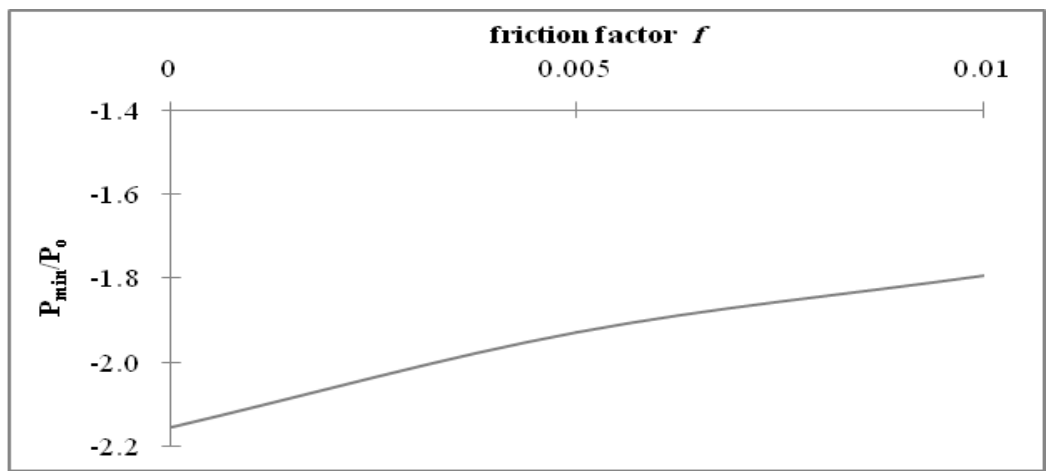

Fig. (12): Dimensionless minimum pressure in the pipe versus the pipe friction factor.

\subsection{Effect of Methods of Protection on Transient Pressure Head}

This section aims to investigate the effect of non-return valve, open surge tank and air chamber on transient pressure head. All variables were taken as constant where friction factor $(f)=0.01$, pipe material is PVC with modules of elasticity $=3.3 \mathrm{GN} / \mathrm{m}^{2}$, pipe wall thickness $1.69 \mathrm{~cm}$, fluid density $(\rho)=1000 \mathrm{~kg} / \mathrm{m}^{3}$ (fluid is water), steady flow velocity $=1 \mathrm{~m} / \mathrm{sec}$. and there is no air in the water.

\subsubsection{Non-Return Valve}

To show the effect of non-return valve on transient pressure head, a non-return valve $0.325 \mathrm{~m}$ diameter and 0.8 head loss coefficient was used at the beginning of the pipeline and was installed exactly after the pump. Figures (13) and (14) indicate the variation in maximum and minimum piezometric heads along the pipeline for no protection and for using non-return valve. Figure (13) shows that the non-return valve, in spite of its protection of the pump, it increases the positive pressure heads along the pipeline. For examples at node A by nearly $124 \%$; at node D by nearly $61 \%$ and at node $\mathrm{E}$ by nearly $54 \%$ so, the beginning of the pipeline is the most affected due to using non-return valve. Figure (14) shows that the non-return valve doesn't affect the minimum pressure heads along the pipeline because the minimum pressure heads occur before the non-return valve effect appears.

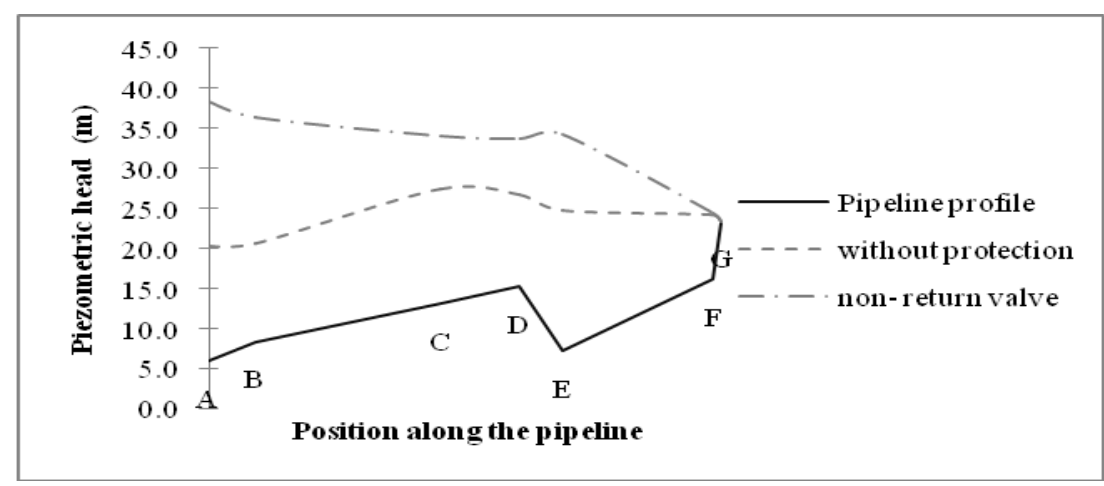

Fig. (13): Maximum piezometric heads along the pipeline due to using non-return valve. 


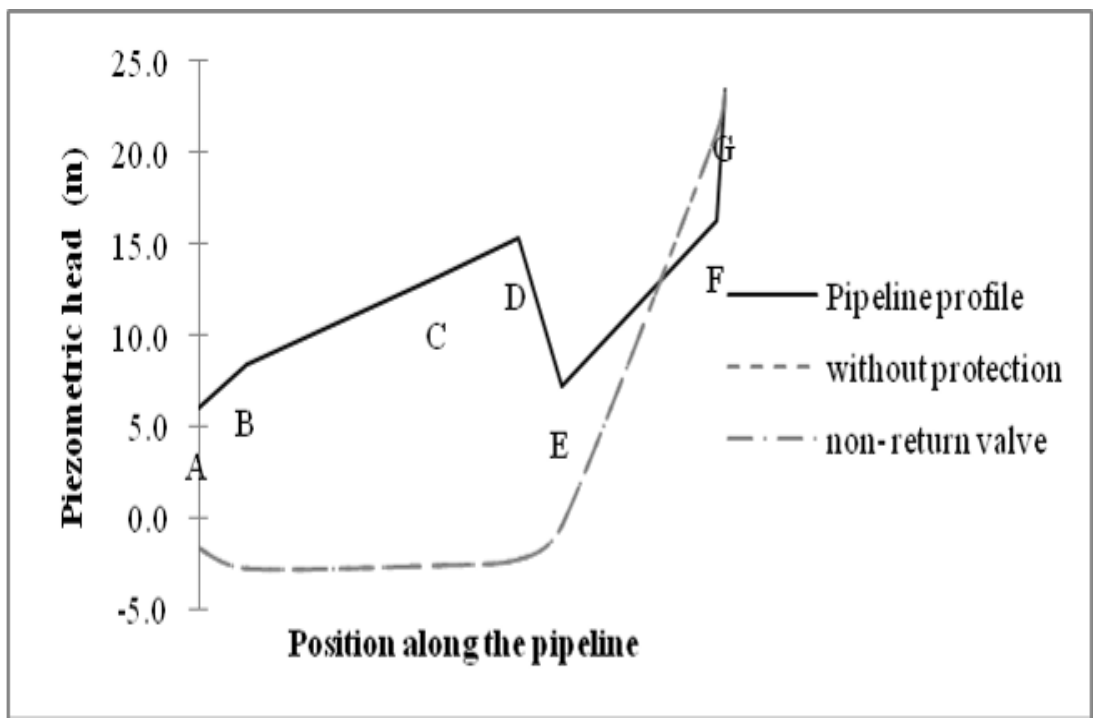

Fig. (14): Minimum piezometric heads along the pipeline due to using non-return valve.

\subsubsection{Open Surge Tank}

To show the effect of open surge tank on transient pressure head, open surge tank 2.5 $\mathrm{m}$ diameter was used at node $\mathrm{A}$; i.e. at beginning of the pipeline and its initial water surface level is $27.61 \mathrm{~m}$ which equal to the sum of node elevation $(6 \mathrm{~m})$ and node A steady state flow pressure head $(21.61 \mathrm{~m})$. Non-return valve $0.325 \mathrm{~m}$ diameter and 0.8 head loss coefficient was used at beginning of the pipeline, as a worst case, because it increases the pressure heads as shown in the previous section. Figures (15) and (16) show the variation in maximum and minimum piezometric heads along the pipeline for no protection, using open surge tank only and using open surge tank and non-return valve simultaneously. Maximum pressure head curves along the pipeline for the second and third cases are correspondent as shown in Fig. (15) so, adding non-return valve to the pipeline when using open surge tank doesn't affect its maximum pressure heads. Maximum pressure head at beginning of the pipeline is greater for the second and third cases than for unprotected pipeline because using open surge tank alone or with nonreturn valve reduces the pressure head regularly. So, the maximum pressure heads in the two cases are approximately equal to the steady state pressure heads on contrary to no protection case where a sudden drop in pressure heads happens exactly after the pump shut down. Figure (15) and Fig. (13) in the previous section show that the open surge tank help in reducing the maximum pressure head which is produced by the nonreturn valve. Figure (16) shows that the open surge tank has a significant effect on the minimum pressure heads along the pipeline and protects it from negative pressures. Using non-return valve and open surge tank together has higher pressure heads than using open surge tank only. 


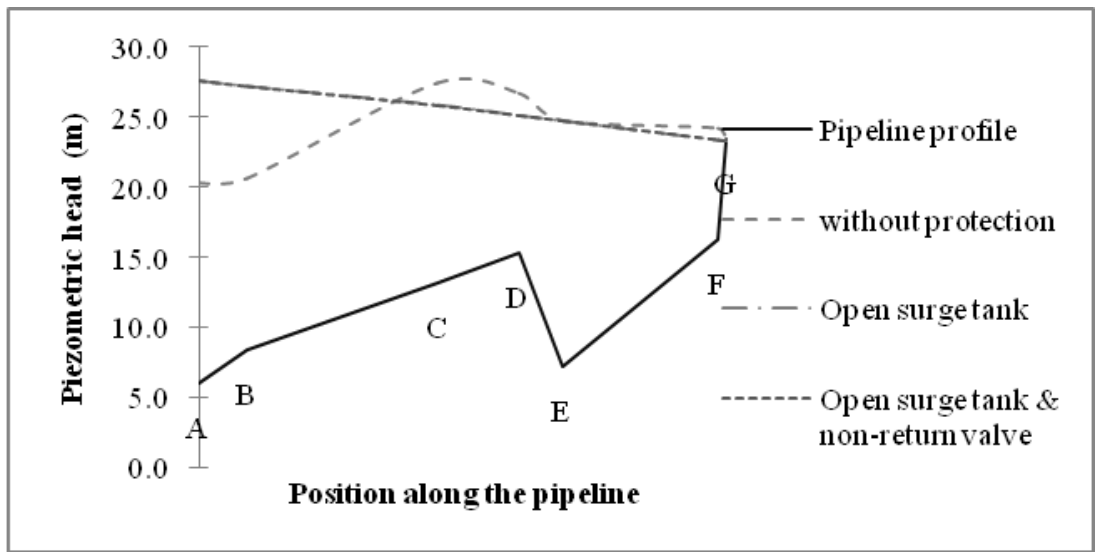

Fig. (15): Maximum piezometric heads along the pipeline due to using open surge tank.

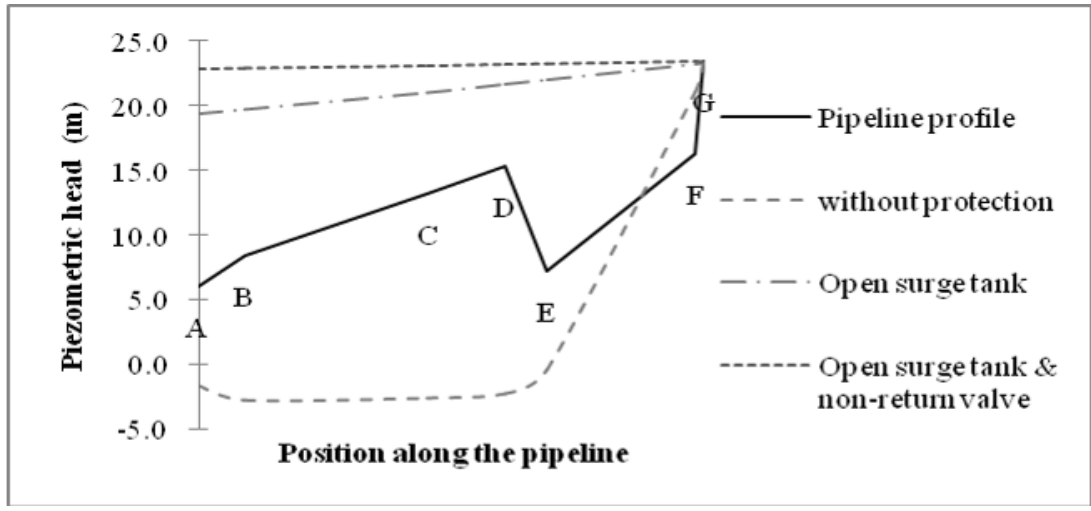

Fig. (16): Minimum piezometric heads along the pipeline due to using open surge tank.

\subsubsection{Air Chamber}

To show the effect of air chamber on transient pressure head, two air chambers $2.5 \mathrm{~m}$ diameters were used simultaneously. The first was used at node A; i.e. at beginning of the pipeline and its initial water surface level and its top level were 8.3 and $10.7 \mathrm{~m}$ respectively. The second was used at node $\mathrm{C}$ i.e. at distance $1140 \mathrm{~m}$ from beginning of the pipeline and its initial water surface level and its top level were 15.4 and $17.7 \mathrm{~m}$ respectively. Non-return valve $0.325 \mathrm{~m}$ diameter and 0.8 head loss coefficient was used at beginning of the pipeline, as a worst case, because it increases the pressure heads as shown previously. Figures (17) and (18) show the variation in maximum and minimum piezometric heads along the pipeline for no protection, using air chamber only and using air chamber and non-return valve simultaneously. Maximum pressure head curves along the pipeline for the second and third cases are correspondent as shown in Fig. (17) so, adding non-return valve to the pipeline when using air chamber doesn't affect its maximum pressure heads. Maximum pressure head at beginning of the pipeline is greater for the second and third cases than for unprotected pipeline because using air chamber alone or with non-return valve reduces the pressure head regularly. So, the maximum pressure heads on the two cases are approximately equal to the 
steady state pressure head on contrary to no protection case, where a sudden drop in pressure heads happens exactly after the pump shut down. Figure (17) and Fig. (13) show that air chamber help in reducing the maximum pressure head which is produced by the non-return valve. Figure (18) shows that the air chamber has a significant effect on the minimum pressure heads along the pipeline and protects it from negative pressures. Using non-return valve and air chamber together has higher pressure heads than using air chamber alone.

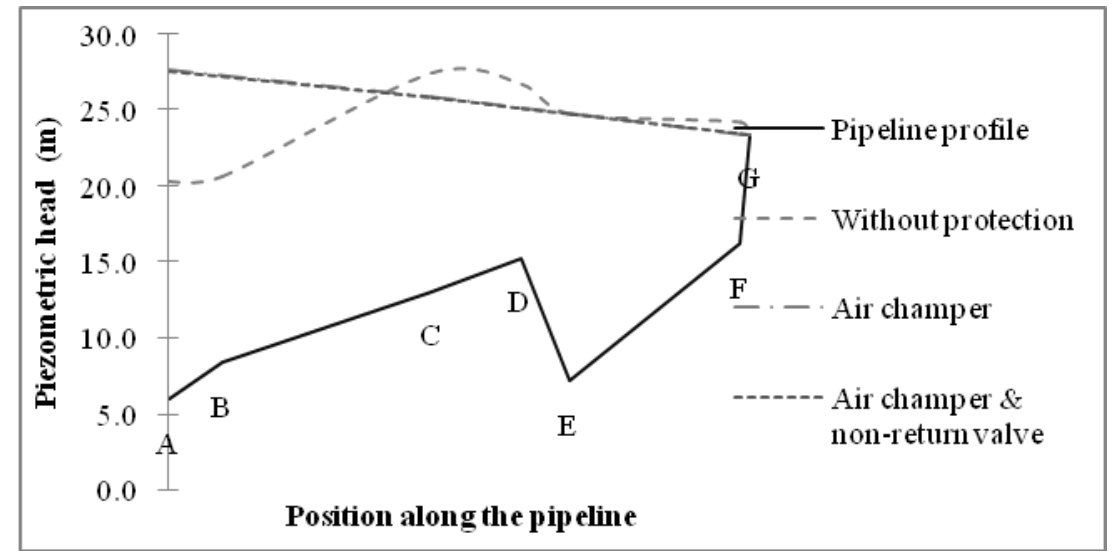

Fig. (17): Maximum piezometric heads along the pipeline due to using air chamber.

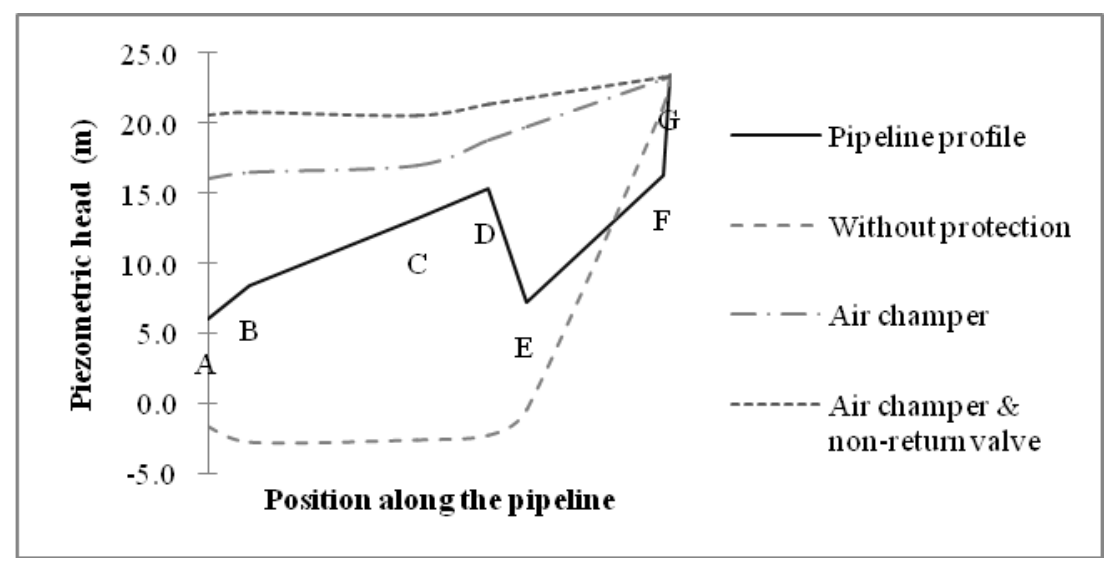

Fig. (18): Minimum piezometric heads along the pipeline due to using air chamber.

\subsection{Effect of Crack Existence in Pipeline on Transient Pressure Head}

This section aims to investigate the effect of leakage or intrusion between inside and outside the pipeline on transient pressure head. A crack is assumed to be at node D which is at distance $1530 \mathrm{~m}$ from beginning of the pipeline and is represented by a totally opened gate valve $2.5 \mathrm{~cm}$ diameter and the underground water surrounding the pipeline is represented by a head boundary. All variables were taken as constant where friction factor $(f)=0.01$, pipe material is PVC with modules of elasticity $=3.3 \mathrm{GN} / \mathrm{m}^{2}$ and wall thickness $1.69 \mathrm{~cm}$, fluid density $(\rho)=1000 \mathrm{~kg} / \mathrm{m}^{3}$ (fluid is water), steady flow 
velocity $=1 \mathrm{~m} / \mathrm{sec}$ and there is no air in the water. Node D is at distance $1530 \mathrm{~m}$ from beginning of the pipeline, its level is $15.3 \mathrm{~m}$ and has an internal maximum and minimum pressure head 11.52 and $-17.71 \mathrm{~m}$ respectively at no crack simulation. If there is an opening in the pipeline at it and the underground water level is $26.82 \mathrm{~m}$ or higher, the only water direction will be from underground water to the pipe. If the underground water level is $-2.41 \mathrm{~m}$ or lower, the only water direction will be from the pipe to the underground water. If the underground water level is between 26.82 and $2.41 \mathrm{~m}$, the water direction will be from the underground water to pipe and reverse. The pipeline was studied first without connection between outside and inside the pipe then intrusion and leakage were allowed and finally a non-return valve was added at beginning of the pipeline to investigate its effect on intrusion and leakage existence.

\subsubsection{Intrusion}

To show the effect of intrusion on transient pressure head, underground water level was assumed $26.82 \mathrm{~m}$. Figures (19) and (20) show the maximum and minimum piezometric heads along the pipeline. Figure (19) shows that intrusion decreases the maximum pressure heads at nodes $\mathrm{D}$ and $\mathrm{E}$ by nearly $5 \%$. Intrusion reduces the maximum pressure heads produced by the non-return valve. Intrusion without and with non-return valve minimum pressure heads are correspondent along the pipeline as shown in Fig. (20). Both cases decrease the minimum pressure heads along the pipeline.

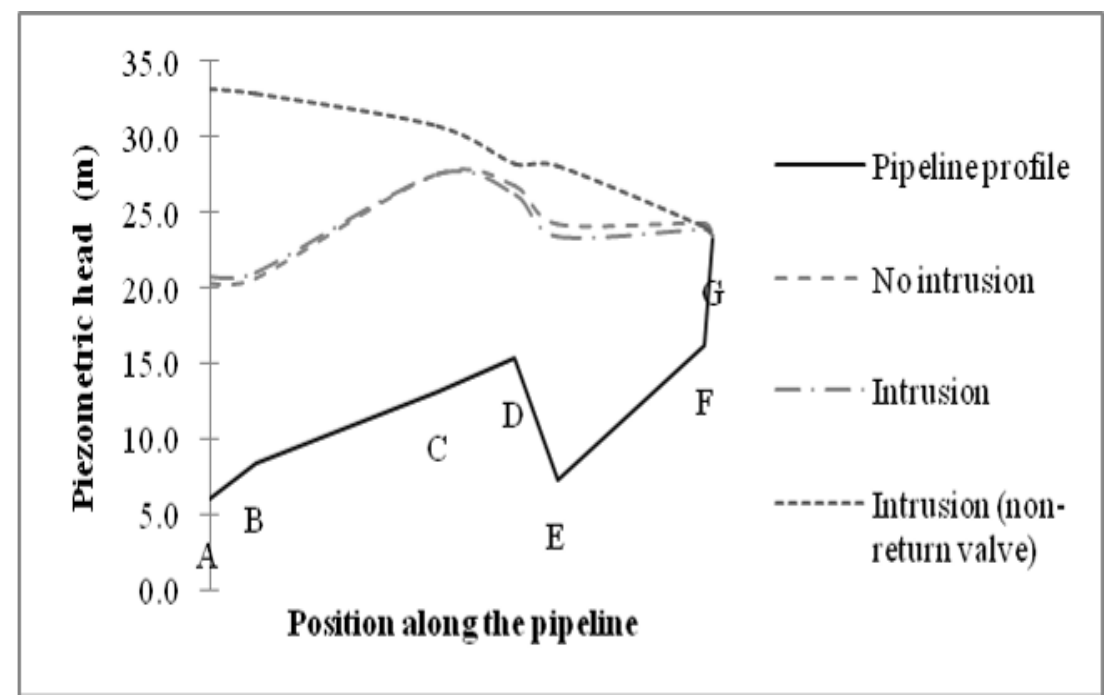

Fig. (19): Maximum piezometric heads along the pipeline due to intrusion. 


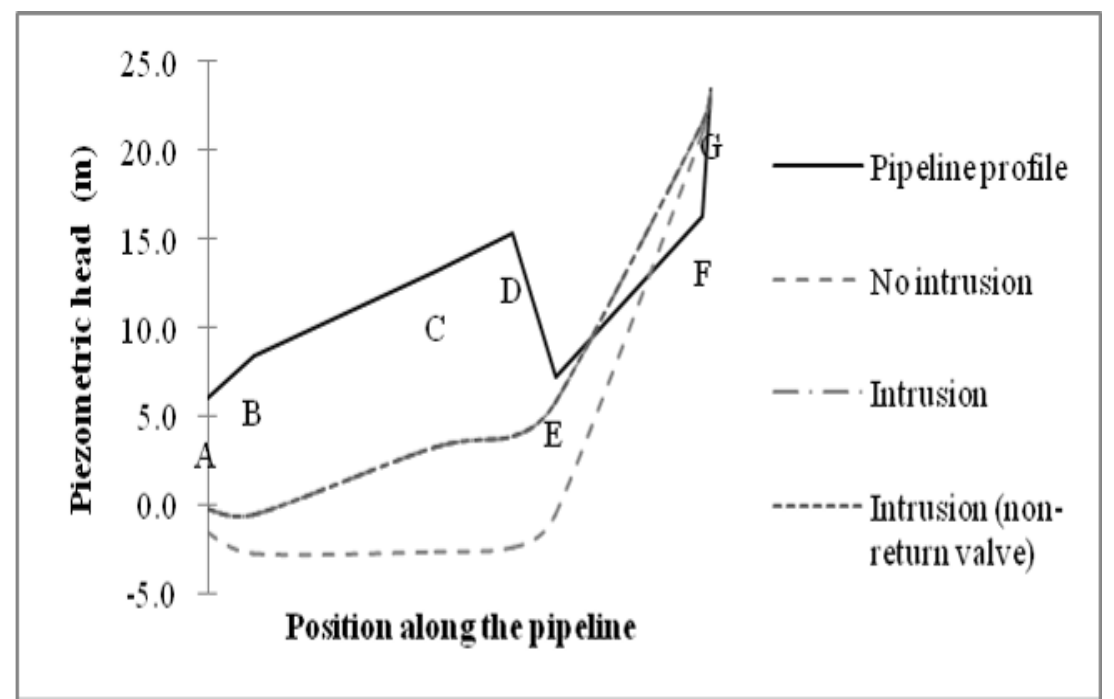

Fig. (20): Minimum piezometric heads along the pipeline due to intrusion.

\subsubsection{Leakage}

To show the effect of leakage on transient pressure head, underground water level was assumed $-2.41 \mathrm{~m}$; i.e. below the minimum pressure head in the pipe. Figures (21) and (22) show the maximum and minimum piezometric heads along the pipeline. Figure (21) shows that leakage decreases the maximum pressure heads along the pipeline, for example at nodes $\mathrm{D}$ and $\mathrm{E}$ by nearly $12 \%$. Leakage reduces the maximum pressure heads produced by the non-return valve. Leakage without and with non-return valve minimum pressure heads are correspondent along the pipeline as shown in Fig. (22). Both cases decrease the minimum pressure heads along the pipeline.

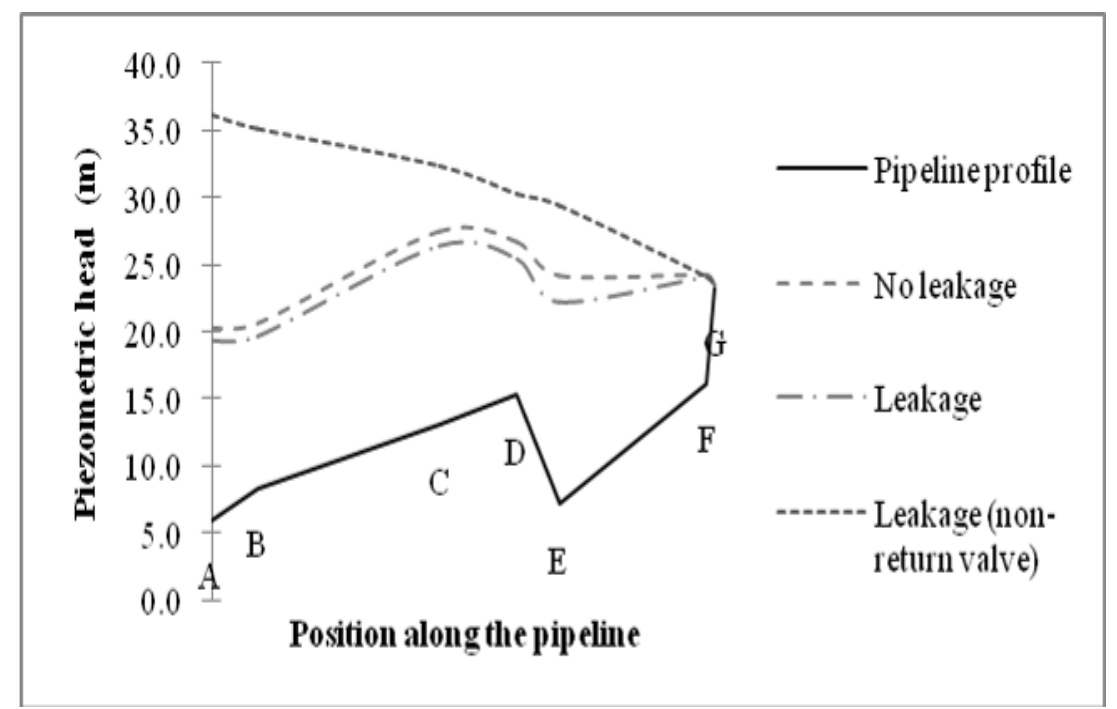

Fig. (21): Maximum piezometric heads along the pipeline due to leakage. 


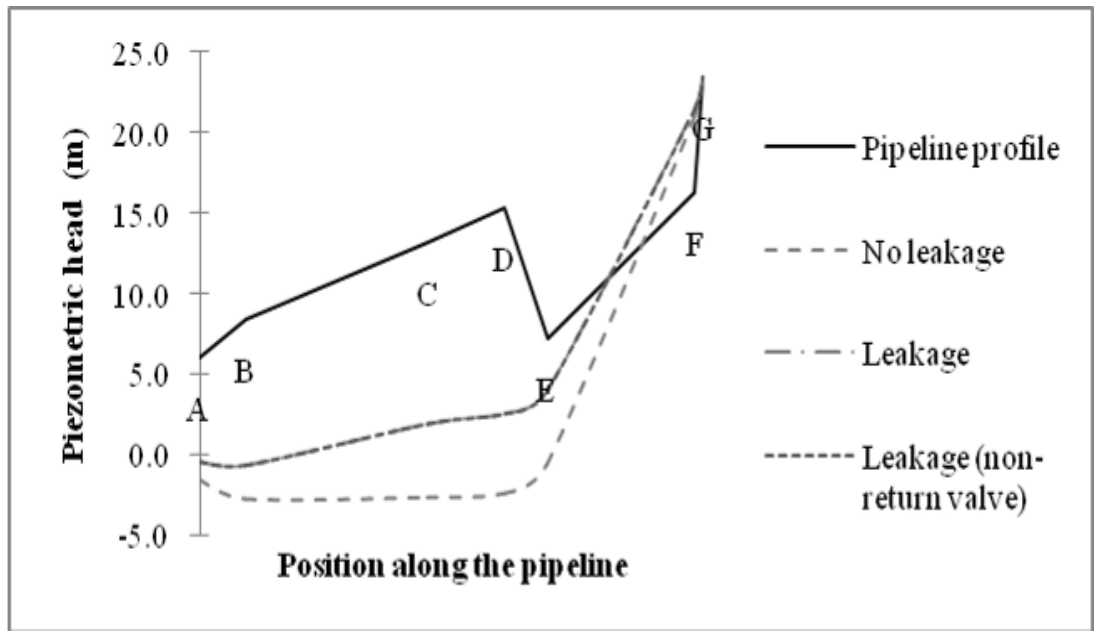

Fig. (22): Minimum piezometric heads along the pipeline due to leakage.

\subsubsection{Intrusion and Leakage}

To show the effect of discharge between inside and outside the pipeline on transient pressure head, underground water level was assumed $25.15 \mathrm{~m}$ which is the sum of node level $(15.3 \mathrm{~m})$ and the pressure head at the node in the steady state flow $(9.85 \mathrm{~m})$. So, in the steady state before pump shut down the flow between outside and inside the pipe is zero. Figures (23) and (24) show the maximum and minimum piezometric heads along the pipeline. Figure (23) shows that leakage or intrusion between inside and outside the pipeline decreases the maximum pressure heads at nodes D and E by nearly $8 \%$ and $5 \%$ respectively. Intrusion and leakage reduce the maximum pressure heads produced by the non-return valve. Second and third cases minimum pressure heads are correspondent along the pipeline as shown in Fig. (24). Both cases decrease the minimum pressure heads along the pipeline.

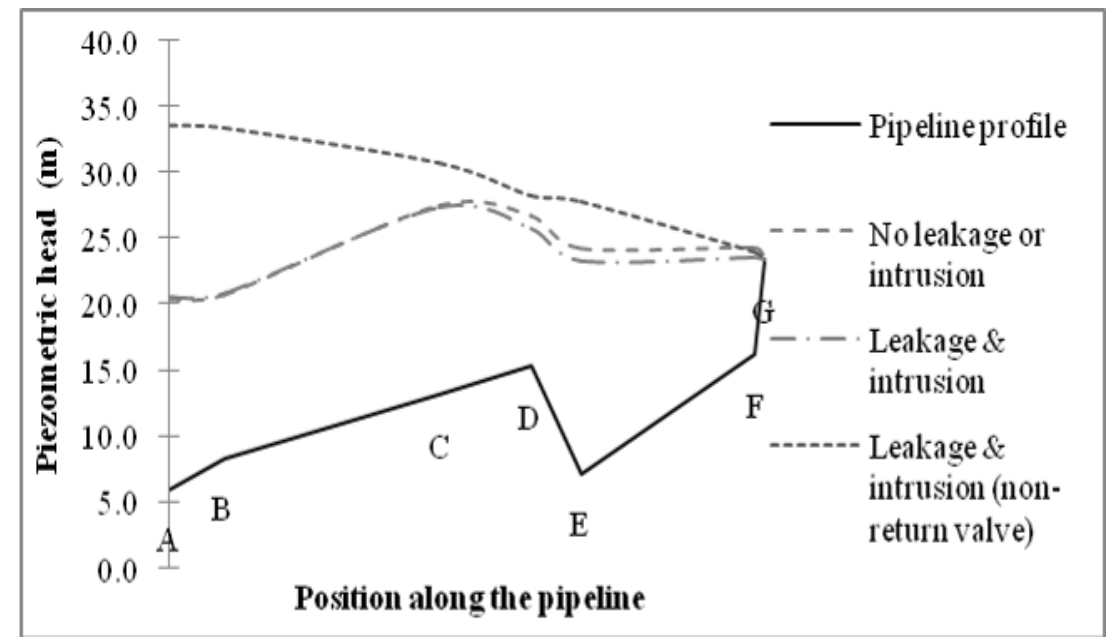

Fig. (23): Maximum piezometric heads along the pipeline due to leakage and intrusion. 


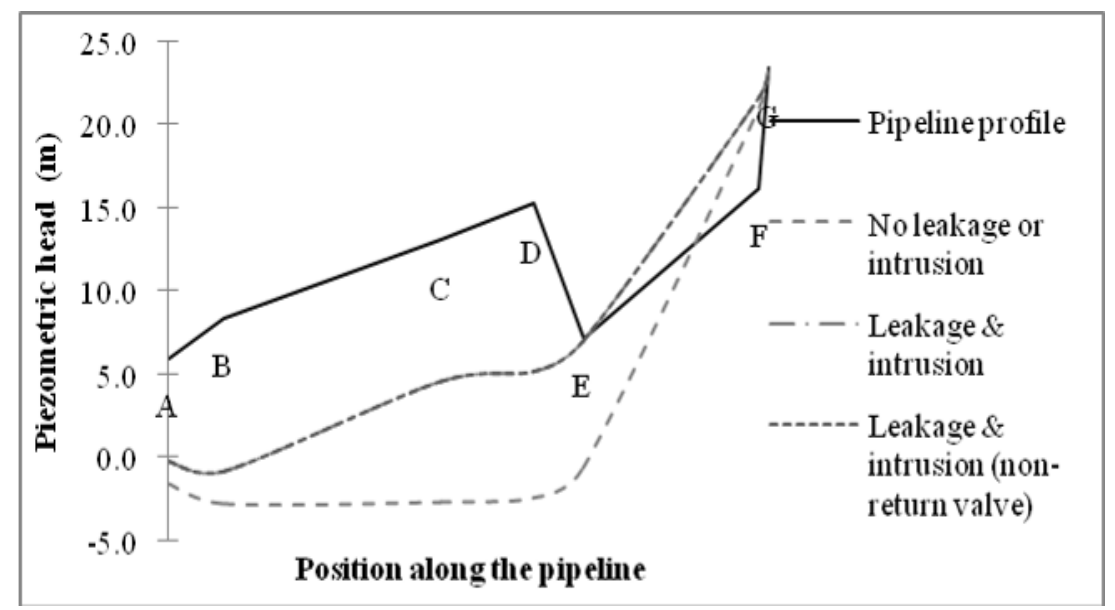

Fig. (24): Minimum piezometric heads along the pipeline due to leakage and intrusion.

\section{5- CONCLUSIONS}

The main conclusions drawn from this study are as follows:

- Fluid density, steady flow velocity, air entrainment, pipeline material type and pipeline friction factor have a noticeable effect on transient pressure head as follows:

$>\mathrm{P}_{\max } / \mathrm{P}_{\mathrm{o}}$ ratio increases due to increase at flow density from 900 to 1000 $\mathrm{kg} / \mathrm{m}^{3}$ then decreases due to increase from 1000 to $1200 \mathrm{~kg} / \mathrm{m}^{3} . \mathrm{P}_{\min } / \mathrm{P}_{\mathrm{o}}$ ratio increases due to the increase at flow density from 900 to $1100 \mathrm{~kg} / \mathrm{m}^{3}$ then decreases due to the increase from 1100 to $1200 \mathrm{~kg} / \mathrm{m}^{3}$.

$>\mathrm{P}_{\max } / \mathrm{P}_{\mathrm{o}}$ ratio increases due to the increase in steady flow velocity and $\mathrm{P}_{\min } / \mathrm{P}_{\mathrm{o}}$ ratio decreases due to the increase in steady flow velocity.

$>\mathrm{P}_{\max } / \mathrm{P}_{\mathrm{o}}$ ratio increases due to the increase in air concentration and $\mathrm{P}_{\min } / \mathrm{P}_{\mathrm{o}}$ ratio decreases due to the increase in air concentration.

$>\mathrm{P}_{\max } / \mathrm{P}_{\mathrm{o}}$ ratio decreases due to the increase in pipe material elasticity from 3.3 to $20 \mathrm{GN} / \mathrm{m}^{2}$ and approximately takes constant value due to the increase from 20 to $210 \mathrm{GN} / \mathrm{m}^{2}$. $\mathrm{P}_{\min } / \mathrm{P}_{\mathrm{o}}$ ratio decreases due to the increase in pipe material elasticity.

$>\mathrm{P}_{\max } / \mathrm{P}_{\mathrm{o}}$ and $\mathrm{P}_{\min } / \mathrm{P}_{\mathrm{o}}$ ratios decrease due to the increase in friction factor.

$>$ The increase in steady flow velocity or air concentration in the fluid increases the time taken by the water hammer wave to dissipate.

- Although the non-return valve protects the pump from water hammer phenomenon, it increases the transient pressure heads and the water hammer wave period in the pipeline.

- The open surge tank and the air chamber protect the pipeline from negative pressures as well as the positive pressures.

- Occurrence of water hammer phenomenon in pipe system may cause intrusion of containment water from outside the pipeline, if crack exist in it.

- Intrusion and leakage existence reduce values of the minimum pressure heads more than the maximum pressure heads. 


\section{REFERENCES}

1. Abd el-Gawad, S. M., (1994), "Water Hammer Analysis for the Pipeline Ahmed Hamdi Tunnel, Abu-Radis", Engng. Res. Jour., Vol. 6, PP. 40-54.

2. Al-Khomairi, A. M., (2005), "Use of the Steady-State Orifice Equation in the Computation of Transient Flow Through Pipe Leaks", The Arabian Jour. for science and Eng., Vol. 30, N. IB, PP. 33-45.

3. Burrows, R. and Qiu, Q., (1995), "Effect of Air Pockets on PipeLine Surge Pressure", Proc. Instn Civ. Engrs Wat., Marit. \& Energy, 112, PP. 349-361.

4. Chaudhry, H. M. and Yevjevich, V., (1981), "Closed-Conduit Flow", water resources publications, P.O. Box 2841, Littleton, Colorado 80161, U.S.A..

5. Fitzgerald, R. and Van Blaricum, V. L., (1998), "Water Hammer and Mass Oscillation (WHAMO) 3.0 user's manual", US Army Corps of Engineers.

6. Jones, G. M. and Bosserman, B. E., (2006), "Pumping Station Design", Elsevier, ISBN: 978-0-7506-7544-4, Third Edition.

7. Jönnsson, L., (1999), "Hydraulic Transient as a Monitoring Device", XXVII IAHR congress, Graz, Austria.

8. Mohamed, H. I., (2003), "Parametric Study for the Water Hammer Phenomenon in Pipelines", $1^{\text {st }}$ Int. Conf. of civil Eng. Science, ICCESI, Assiut, Egypt.

9. Parmakian, J., (1963), "Water Hammer Analysis", Dover Publications, New York.

10. Ramos, H., Covas, D., Borga, A. and Loureiro, A., (2004), "Surge Damping Analysis in Pipe Systems: Modeling and Experiments", Vol. 42, No. 4, PP. 413425.

11. Richard C. and Svindland, P. E., (2005), "Predicting the Location and Duration of Transient Induced Low or Negative Pressures within a Large Water Distribution System", Master's thesis, Lexington, Kentucky.

12. Samani, H. M. V. and Khayatzadeh, A., (2002), "Transient Flow in Pipe Networks", Jour. of Hydr. Research, Vol. 40, No. 5, PP. 637-644.

13. Sharp, B. B. and Sharp D. B., (1996), "Water Hammer: Practical Solutions", Butterworth- Heinermann, ISBN: 0340645970.

14. Simpson, A. R. and Wu, Z. Y., (1997), "Computer Modelling of Hydraulic Transient in Pipe Networks and Associated Design Criteria", MODSIM97, International Congress on Modelling and Simulation, Modelling and Simulation Society of Australia, Hobart, Tasmania, Australia.

15. Stephenson, D., (2002), "Simple Guide for Design of Air Vessels for Water Hammer Protection of Pumping Lines", Jour. of Hyd. Eng., Vol. 128, No. 8, PP. 792-797.

16. Yang, K., (2001), "Practical Method To Prevent Liquid Column Separation”, Jour. of Hyd. Eng., Vol. 127, No. 7, PP. 620-623. 


\section{دراسة السريان الغير مستقر في أنظمة المواسير المضغوطة و طرق الحماية لها}

من المهم أخذ ظاهرة المطرقة المائية في الاعنبار عند تصميم الكثير من الأنظمة الهيدروليكية وهذا يعود

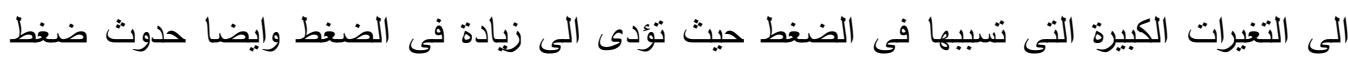

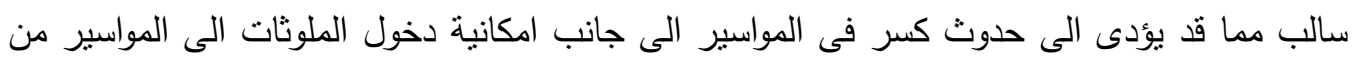
المياه الجوفية الخارجية.

هذه الدراسة تتقم الى ثلاثة اجزاء. الجزء الاول من الدراسة يناقش نأثير بعض المتغيرات المختلفة علي

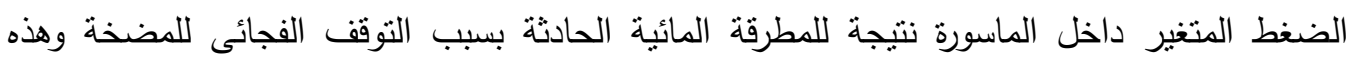

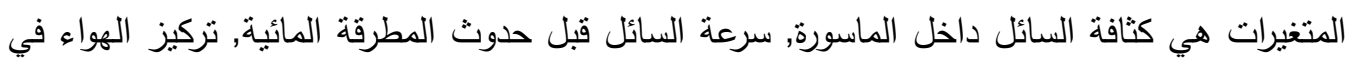

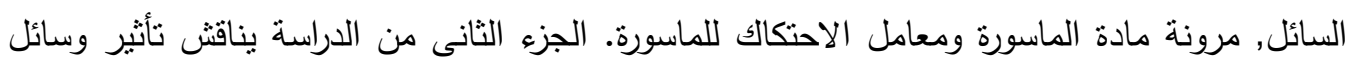

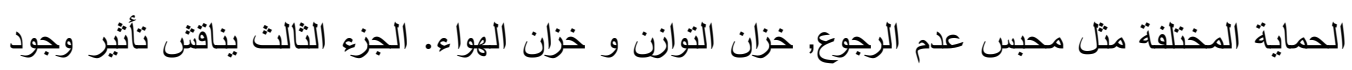

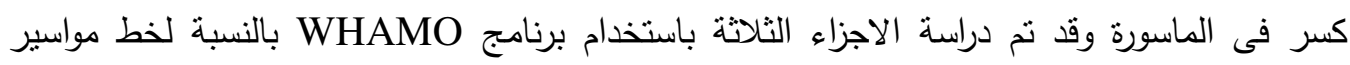

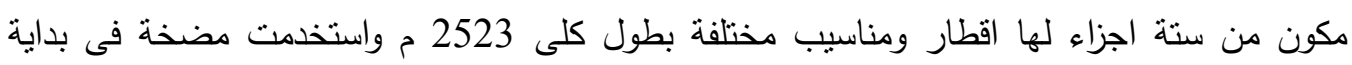
الخط لضخ السائل الي خزان منسوب السائل ثابت داخله فى نهاية الخط.

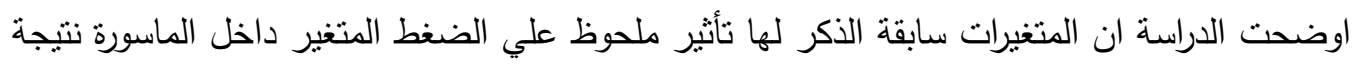

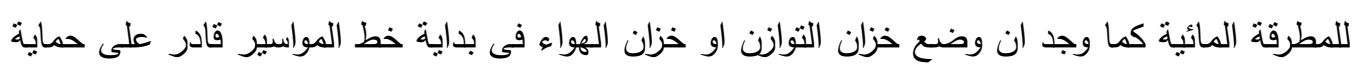

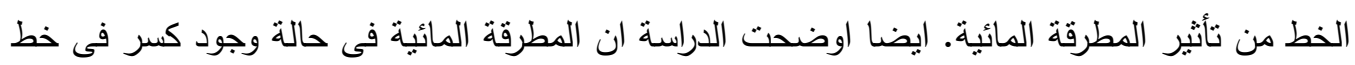
المواسير قد تسبب دخول المياه من خارج الماسورة الى داخلها او تسربها من داخل الماسورة الى خارجها او حدوث كلاهما. 